Como citar: CHAVES, Vinicius Figueiredo Chaves. SOARES, Abel Rafael. Análise Crítica da Aplicação do Termo de Compromisso como Instrumento Regulatório do Mercado de Capitais. Revista do Direito Público. Londrina, v.11, n.1, p.61-84, jan/abr.2016. DOI: $10.5433 / 1980-511 \mathrm{X}$. 2016v11n1p61. ISSN: 1980$511 X$.

* Doutorando em Direito pela UERJ, na linha de pesquisa Empresa e Atividades Econômicas. Mestre em Direito Público e Evolução Social pela UNESA. E-mail: chavesvinicius2013@gmail. com

**Mestre em Direito Público e Evolução Social pela UNESA. Pós-graduado em Direito Processual Civil pela UCAM. E-mail: rafa.soares @uol.com.br

\section{Análise crítica da aplicação do termo de compromisso como instrumento regulatório do mercado de capitais}

\author{
Critical appraisal of The APPlication OF THE \\ CONSENT DECREE AS A REGULATORY INSTRUMENT \\ OF CAPITAL MARKET \\ * Vinicius Figueiredo Chaves \\ ** Abel Rafael Soares
}

Resumo: Apoiado em pesquisa bibliográfica, documental e de levantamento de dados, realiza-se uma abordagem sobre a disciplina jurídica do mercado de capitais, tendo como base a análise crítica do instrumento regulatório conhecido como termo de compromisso (acordo substitutivo). Percebeu-se que, em conformidade com o art. $11, \S 5^{\circ}$, da Lei ${ }^{\circ} 6.385 / 76$, as normas regulatórias editadas pela CVM, que regem o processo administrativo sancionador nos ritos ordinário e sumário, prescrevem que, quando da intimação dos acusados, advirá a advertência de que estes poderão propor a celebração de termo de compromisso. Aceita a proposta e cumprido o acordo, este não importará confissão quanto à matéria de fato, nem reconhecimento de ilicitude da conduta analisada. Do exame dos PAS instaurados entre 2009 e 2014 , chegou-se ao número total de 405 termos aprovados pelo órgão regulador, resultados que caracterizam uma acentuada utilização deste instrumento regulatório. Do que foi analisado, conclui-se que, embora o acordo possa ser compreendido como um importante mecanismo no âmbito da regulação do mercado de capitais, o seu uso demasiado implica em desvirtuamento de suas finalidades, dos fundamentos da disciplina normativa do mercado e do conjunto de funções atribuídas à CVM.

Palavras-chave: Mercado de capitais; Regulação; Processo administrativo sancionador; Termo de compromisso.

Abstract: Supported by literature research, document and data
collection, it is carried out an approach to the legal regulation of
capital market, based on the review of regulatory instrument
known as consent decree. It was noticed that, in accordance
with Article $11, \S 5^{\circ}$ of Law $N^{\circ} .6 .385 / 76$, the rules issued by
Brazilian Securities and Exchange Comission (CVM), which
governs administrative sanctioning proceedings in ordinary and 
summary rites, prescribe that, when summons to an accused, a warning they may propose a term of commitment will follow. Anyways, once an offer is accepted and an agreement is in place, it does not imply into a confession to the facts nor a recognition of the illicit nature of investigated conduct. As of the examination of already established administrative sanctioning proceedings between 2009 and 2014, it is found total number of 405 terms approved by the regulator, results that feature a wide use of this regulatory instrument. From all that is analyzed, it is concluded that, although such an agreement can be recognized as an important mechanism in the context of capital market regulation, its excessive use implies to a distortion of its purposes, of foundations of normative discipline of the market, and of the set of functions assigned to the CVM.

Keywords: Capital market; Regulation; Administrative sanctioning proceedings; Consent decree. 


\section{INTRODUÇÃO}

No Brasil, as relações entre o órgão regulador do mercado de capitais, a Comissão de Valores Mobiliários (CVM), e os agentes de mercado têm se modificado ao longo dos anos, com uma maior aproximação decorrente do surgimento de instrumentos como a audiência pública e o termo de compromisso (acordo substitutivo), que caracterizam uma maior abertura do sistema normativo. No caso do acordo substitutivo, a autoridade reguladora se encontra autorizada por lei até mesmo a negociar com os acusados, para suspender e encerrar processos, o que caracteriza reação alternativa (celebração de termo de compromisso) à pura e simples aplicação de penalidades (advertências, multas, suspensões etc.) previstas em lei.

A academia não pode ficar à margem deste debate, sendo premente estudar as questões que lhe são direta ou indiretamente relacionadas, descortinando-se nova e instigante linha de pesquisa, a qual tem o termo de compromisso (TC) como pano de fundo a subsidiar inúmeras discussões teóricoconceituais, tanto do ponto de vista das reflexões sobre a conveniência do modelo, em si, como também no que diz respeito à adequação da forma de sua utilização pelo órgão regulador.

No caso específico deste trabalho, o objetivo geral é realizar uma abordagem sobre a disciplina jurídica do mercado de capitais, tendo como base a questão central da análise da forma como o referido instrumento regulatório vem sendo aplicado por parte da Comissão de Valores Mobiliários (previsões legais e regulatórias contemplam a possibilidade de o acusado, no âmbito do processo administrativo sancionador -PAS, propor a celebração de termo de compromisso, que pode ser aprovado ou rejeitado pela CVM). Neste sentido, formula-se o seguinte problema de pesquisa: a CVM, quando da utilização do termo de compromisso no âmbito do processo administrativo sancionador (PAS), tem atuado segundo as finalidades deste mecanismo de regulação, os fundamentos da disciplina normativa do mercado e também do conjunto de funções que lhe são atribuídas?

A fim de analisar a questão formulada, fez-se revisão da literatura já publicada sobre o tema geral e também acerca do recorte específico proposto. Para enriquecer a abordagem, realizou-se busca documental nos planos legal e regulatório, assim como levantamento, consolidação e análise de dados empíricos sobre os termos de compromisso celebrados pelo órgão regulador brasileiro, com foco no período compreendido entre 2009 e 2014. 
O trabalho está dividido da seguinte forma: i) revisão da literatura sobre as funções e segmentos do mercado de capitais, dos principais fundamentos do conjunto de prescrições jurídicas que o disciplinam, assim como das características do órgão regulador brasileiro, a Comissão de Valores Mobiliários (CVM); ii) exame dos fundamentos legais e do arcabouço regulatório do processo administrativo sancionador (PAS), com foco no mecanismo conhecido como termo de compromisso (acordo substitutivo); iii) levantamento de dados empíricos sobre os termos de compromisso celebrados no período compreendido entre os anos de 2009 e 2014, sendo as informações consolidadas e apresentadas no trabalho, com detalhamento dos números de acordos celebrados em cada ano e o número total; iv) análise crítica da forma de utilização deste instrumento regulatório pela Comissão de Valores Mobiliários.

\section{BREVES NOÇÕES SOBRE O MERCADO DE CAPITAIS E A SUA DISCIPLINA JURÍDICA}

O mercado de capitais engloba as mais diversas operações com valores mobiliários ${ }^{1}$ de emissão de sociedades anônimas de capital aberto. $\mathrm{O}$ objetivo principal é obter financiamento para as companhias já existentes ou que estejam sendo constituídas, e assim possibilitar o desenvolvimento de seus projetos empresariais.

Esta estrutura propicia um ambiente que põe em contato diversos sujeitos econômicos: agentes poupadores, que possuem recursos em excesso; e agentes tomadores, que necessitam de capital. Há também aqueles que simplesmente procuram investir os recursos de que dispõem mediante a aquisição de títulos, com finalidade de obtenção de rentabilidade para o capital investido. Trata-se de importante fator no processo de mobilização de recursos e de sua canalização para os investimentos (VASCONCELLOS, 2005).

Segundo a literatura, o mercado se subdivide em dois segmentos, sendo um de emissão e o outro de negociação de títulos. No mercado primário, operase o lançamento de valores mobiliários emitidos pelas companhias, operações que implicam na oferta de novos títulos ao público investidor (KÜMPEL, 2007).

\footnotetext{
No Brasil, não existe um conceito legal que defina valor mobiliário. No artigo $2^{\circ}$ da Lei 6.835/76, que dispõe sobre o mercado de valores mobiliários e criou a Comissão de Valores Mobiliários, foi inserido um rol exemplificativo, que inclui uma série de títulos de naturezas diversas, como as ações, debêntures e bônus de subscrição, entre outros.
}

Revista do Direito Público, Londrina, v.11, n.1, p.61-84, jan./abr.2016 | DOI: 10.5433/1980-511X.2016v11n1p61 
Quem os vende, portanto, são as próprias companhias emissoras, que irão utilizar o produto da venda para financiar seus investimentos (ASSAF NETO, 2012). Como advertem Elias e Gama (apud CASTRO, 1979), a função primordial deste segmento consiste na captação de recursos para os agentes econômicos mediante a emissão ${ }^{2}$ destes títulos, que podem ser subscritos pelos próprios acionistas ou colocados em oferta pública, a partir da qual qualquer investidor poderá adquiri-los.

Por sua vez, o mercado secundário ${ }^{3}$ registra operações que "representam transferências de recursos e títulos entre investidores e/ou instituições" (ELIAS; GAMA, 1979, p. 141), sem impactos diretos para as sociedades emitentes. Este segmento de negociação permite ao investidor converter o investimento realizado, transformando-o novamente em dinheiro (LAMEIRA, 2003), para assim reaver o capital aplicado, possibilitando liquide $z^{4}$ aos ativos adquiridos no mercado primário. Neste sentido, o mercado de negociação é de fundamental para a garantia do sucesso de uma determinada emissão e, num contexto mais amplo, do próprio mercado primário.

O regular e eficiente funcionamento do mercado de capitais depende do estabelecimento de um conjunto adequado de prescrições jurídicas que disciplinam as operações realizadas e as condutas dos agentes econômicos que transacionam neste âmbito, seja nas ofertas iniciais ou secundárias de valores mobiliários ou mesmo nas subsequentes operações de compra e venda, entre outras. A esse conjunto de normas e regras dá-se o nome de Direito do Mercado de Capitais.

\footnotetext{
2 A emissão pública deve ser realizada, em regra, com a intermediação de instituições integrantes do sistema de distribuição de valores mobiliários, conhecidas como "intermediárias", tais como bancos de investimento, sociedades corretoras e sociedades distribuidoras. O referido processo é chamado de underwriting. Normalmente se forma um "pool" de instituições para a operação. A participação em questão é fundamental ao sucesso da colocação pública, pois as instituições auxiliam diretamente os emissores no cumprimento das exigências e requisitos formulados pela Comissão de Valores Mobiliários no que tange às ofertas de distribuição.

$3 \mathrm{O}$ mercado secundário funciona principalmente nas bolsas de valores, instituições administradoras de mercados, onde são efetuadas operações envolvendo valores mobiliários. As Bolsas de Valores integram o sistema de distribuição de valores mobiliários, sob a supervisão do órgão regulador. A elas cabe propiciar um ambiente adequado à realização de negócios com valores mobiliários, além de atuar como órgão auxiliar na fiscalização dos respectivos membros e das operações com valores mobiliários nela realizadas, bem como evitar a manipulação de preços e detectar movimentos anormais de mercado, entre outras funções.

${ }^{4}$ A liquidez é um conceito econômico que, em linhas gerais, indica a possibilidade de transformação de um ativo em dinheiro. Trata-se de um dos fatores que tornam o mercado de capitais atrativo aos olhos dos investidores, na medida em que lhes permite negociar a sua titularidade a qualquer tempo, junto a outros investidores interessados na sua aquisição. Quanto maior a facilidade de negociação de um determinado ativo a preço de mercado, maior será a sua liquidez.
}

Revista do Direito Público, Londrina, v.11, n.1, p.61-84, jan./abr.2016 | DOI: 10.5433/1980-511X.2016v11n1p61 
De acordo com a doutrina de Kümpel (2007), é possível identificar três pontos principais como objeto de sua regulamentação, sendo que o de maior relevância engloba a organização jurídica de certos segmentos do mercado e a determinação das condições para a negociação de valores mobiliários, com vistas à proteção de sua capacidade funcional. Segundo o autor, este ramo da ciência jurídica pertence ao Direito Econômico e é penetrado fortemente por normas de Direito Público, em função do acentuado interesse coletivo no que diz respeito à existência de mercados tão eficientes quanto possível. Assim, seriam dois os objetivos primordiais da regulamentação do Direito do Mercado de Capitais: i) a proteção da sua capacidade funcional (escopo prioritário); e, em decorrência, ii) a proteção do investidor.

A proteção da capacidade funcional do mercado, enquanto bem jurídico a ser prioritariamente protegido, em busca da maximização de sua eficiência, requer a aplicação de algumas medidas adequadas: i) capacidade funcional institucional (que consiste nas condições básicas para a existência de uma série de mecanismos eficientes nos diversos segmentos do mercado, a partir de sua abertura de forma a possibilitar o acesso da oferta e da demanda, e assim permitir a canalização da maior parte possível dos capitais ao mercado e a sua captação pelos agentes econômicos, suprindo as suas necessidades de financiamento. Para tanto, são necessárias condições jurídicas básicas, medidas voltadas à preservação e incremento da confiança dos investidores, aspecto que dependerá da transparência, estabilidade, tratamento equitativo no acesso às informações, justiça e integridade dos segmentos de mercado); b) capacidade funcional operacional (relacionada à necessidade de redução de custos para emitentes de valores mobiliários e também para os investidores, já que a questão dos custos afeta diretamente as decisões de ambas as partes. É preciso, assim, diminuir tanto as despesas dos emitentes quando da colocação dos valores mobiliários no mercado, quanto os encargos financeiros do público investidor); e c) capacidade funcional alocativa (no sentido de assegurar que os recursos/capitais, considerada a sua escassez, sejam fluídos para as alternativas mais relevantes do ponto de vista do desenvolvimento, impulsionando a execução de projetos transformadores da realidade social) (KÜMPEL, 2007).

Por seu turno, a proteção do investidor, como bem jurídico adicional, desdobraria-se na defesa, por intermédio do Direito do Mercado de Capitais: a) do conjunto indeterminado de investidores (a defesa do público investidor, atual e também futuro, visto que o potencial de realização de negócios é de extrema 
importância para a liquidez do mercado, com reflexos positivos na sua capacidade funcional); e b) proteção excepcional do interesse individual do investidor, por meio de pretensões de reparação de danos (proteção jurídica em benefício dos investidores, individualmente, por ocasião dos negócios de compra e venda de valores mobiliários realizados, e não do público investidor em geral) (KÜMPEL, 2007).

O Direito do Mercado de Capitais, portanto, irá englobar normas provenientes do Poder Legislativo e as chamadas normas regulatórias, criadas por órgãos especiais constituídos para o exercício de funções específicas. No Brasil, o órgão regulador do mercado de capitais é a Comissão de Valores Mobiliários.

\section{A COMISSÃO DE VALORES MOBILIÁRIOS E O SEU PAPEL COMO ÓRGÃO REGULADOR DO MERCADO DE CAPITAIS BRASILEIRO}

A Comissão de Valores Mobiliários foi criada pela Lei $n^{\circ} 6.385 / 76^{5}$. Tratase de uma autarquia federal em regime especial ${ }^{6}$, vinculada ao Ministério da Fazenda, que goza de personalidade jurídica e patrimônio próprio. É dotada de autoridade administrativa independente, ausência de subordinação hierárquica, mandato fixo e estabilidade de seus dirigentes, além de autonomia financeira e orçamentária. Até a data de sua instituição, não havia uma entidade específica que absorvesse a regulação e fiscalização do mercado de capitais (FORTUNA, 2002), sendo tais funções então atribuídas ao Banco Central ${ }^{7}$.

\footnotetext{
Antes da criação da CVM, foram importantes as Leis 4.595/64, 4.728/65 que, junto com as Leis $6.385 / 76$ e $6.404 / 76$, estruturaram o sistema financeiro nacional.

${ }^{6}$ Segundo Moreira Neto (1998, p. 186), a autarquia pode ser conceituada como "uma entidade da administração indireta, criada por lei, com personalidade de direito público, descentralizada funcionalmente do Estado para desempenhar atribuições estatais próprias e específicas, com autonomia patrimonial, administrativa e financeira". Prosseguindo, o autor aponta que a característica mais importante está na especialização destes órgãos e funções para atenderem determinados interesses públicos. Gasparini (2009, p. 327) adverte que a locução autarquia de regime especial não encontra o seu conceito na lei, e a doutrina tem procurado delineá-la a partir de seu regime jurídico, por possuir "maiores privilégios que as autarquias comuns". Para Nazar (2009, p. 48), "autarquia de regime especial é toda aquela que a lei instituidora conferir privilégios específicos e aumentar sua autonomia comparativamente com as autarquias comuns, sem infringir os preceitos constitucionais".

${ }^{7}$ Quanto a este aspecto, interessante assinalar as considerações de Whyte (1987, p. 23): "Como nessa época o mercado de valores mobiliários tinha uma expressão relativamente pequena, não se considerou ainda necessário dotá-lo de um órgão regulador próprio, de modo que o Banco Central, cujas atribuições principais eram o controle dos meios de pagamento e a fiscalização das instituições bancárias, foi encarregado também de regular esse mercado".
}

Revista do Direito Público, Londrina, v.11, n.1, p.61-84, jan./abr.2016 | DOI: 10.5433/1980-511X.2016v11n1p61 
A condição de entidade autárquica em regime especial, é importante frisar, adveio apenas com a edição da Medida Provisória $n^{\circ} 8$, convertida na Lei $n^{\circ} 10.411 / 02$, diploma legal a partir do qual passou a ostentar o status de agência reguladora (EIZIRIK et al, 2011). Até então, não era incomum encontrar na doutrina quem lhe negasse tal natureza ${ }^{8}$.

Tendo a lei dotado-a de características inerentes a tais entidades, a ela deverá ser dispensado tratamento proporcional a esta natureza, especialmente no que tange à possibilidade de expedição de normas reguladoras do mercado de valores mobiliários brasileiro. Neste sentido, ao examinar os artigos $3^{\circ}, 4^{\circ}$ e $8^{\circ}$ da Lei 6.385/76, Kümpel (2007) esclarece que a competência da CVM engloba tanto a regulamentação do mercado de valores mobiliários quanto a fiscalização permanente das atividades e dos serviços desenvolvidos nesse segmento, assim como a veiculação de informações sobre o próprio mercado e acerca daqueles que dele participam, bem como dos valores mobiliários nele negociados.

De uma forma geral, pode-se dizer que a autarquia exercerá as suas funções, a fïm de: i) assegurar o funcionamento eficiente e regular dos mercados de bolsa e de balcão; ii) proteger os titulares de valores mobiliários contra emissões irregulares e atos ilegais de administradores e acionistas controladores de companhias ou administradores de carteira de valores mobiliários; iii) evitar ou coibir modalidades de fraude ou manipulação destinadas a criar condições artificiais de demanda, oferta ou preço de valores mobiliários negociados no mercado; iv) assegurar o acesso do público a informações sobre valores mobiliários negociados e as companhias que os tenham emitido; v) assegurar a observância de práticas comerciais equitativas no mercado de valores mobiliários; vi) estimular a formação de poupança e sua aplicação em valores mobiliários; vii) promover a expansão e o funcionamento eficiente e regular do mercado de ações e estimular as aplicações permanentes em ações do capital social das companhias abertas ${ }^{9}$.

\footnotetext{
Bockmann Moreira (1999, p. 141-142), ao analisar, em artigo publicado em 1999, antes, portanto, do advento da referida Lei, a natureza jurídica do Conselho Monetário Nacional, do Banco Central do Brasil e da Comissão de Valores Mobiliários, negava-lhes o status de agências reguladoras, nos seguintes termos: “... parece-nos inviável atribuir a tais pessoas administrativas o título de "agências reguladoras independentes", pois o vínculo funcional e gerencial com a Administração direta impossibilita tal classificação. Em verdade, nem sequer são "Agências Administrativas", mas órgãos que se submetem aos tradicionais conceitos de "desconcentração" (CMN) e "descentralização" (BACEN e CVM)".

${ }^{9}$ Fonte: CVM. Disponível em: <http://www.cvm.gov.br>. Acesso em: 25 jul. 2015.
}

Revista do Direito Público, Londrina, v.11, n.1, p.61-84, jan./abr.2016 | DOI: 10.5433/1980-511X.2016v11n1p61 
A CVM, criada com a finalidade de disciplinar, fiscalizar e desenvolver o mercado de capitais, encontra na função regulatória ${ }^{10}$ uma de suas atribuições primordiais ${ }^{11}$. Com autonomia e agilidade, deverá regular as complexas e dinâmicas relações econômico-financeiras estabelecidas no âmbito em questão ${ }^{12}$, pautando a sua atividade em um conjunto de princípios que levam em conta uma série de fundamentos, identificados como fatores-chave para a promoção das condições consideradas fundamentais para a sua expansão e desenvolvimento. Tais objetivos dependem da eficiência e confiabilidade do mercado, fruto da garantia de níveis adequados de proteção e harmonização dos interesses de todos os agentes econômicos que nele transacionam. Tais fundamentos são:

Interesse público: a transferência de recursos entre os investidores e os agentes econômicos é indispensável à contínua formação de capital, quando se contempla uma sociedade como a brasileira, que exerceu opção clara pelo modelo capitalista, baseado na livre iniciativa e na economia de mercado. É através desse processo de transferência de recursos que se obtém o investimento e o crescimento das unidades econômicas e, em decorrência, do conjunto da sociedade. Portanto, é do interesse público o bom funcionamento do mercado de valores mobiliários.

\footnotetext{
${ }^{10} \mathrm{Na}$ doutrina, é possível encontrar autores que operam a distinção entre regulamentação e regulação. Neste trabalho, trataremos a regulação em sentido lato, vale dizer, de forma mais ampla, englobando tanto a regulamentação quanto a regulação em sentido estrito. Sobre o tema, interessante destacar o posicionamento de Rosa (2012, p. 103), para quem a competência atribuída à Comissão de Valores Mobiliários pode ser definida como híbrida, englobando tanto a regulamentação quanto a regulação. Ao regulamentar, a autarquia estaria pormenorizando o conteúdo dos princípios e regras estipulados nas Leis $\mathrm{n}^{\mathrm{o}}$ 6.385/76 e 6.404/76. Por outro lado, ao regular supriria eventuais lacunas ou omissões destes diplomas legais. Segundo a autora, o poder regulador, denominado competência suplementar, manifesta-se na "possibilidade de a CVM integrar o sistema jurídico, de forma a preencher lacunas normativas advindas de situações novas no mercado de capitais, cuja complexidade e dinamismo o legislador ordinário não poderia antever". Prosseguindo, a autora destaca que o poder regulador "deverá ser exercido dentro dos limites impostos pelo artigo $4^{\circ}$ (da Lei ${ }^{\circ}$ 6.385/76, grifamos) e da Constituição Federal".

${ }^{11}$ Interessante destacar uma definição de Medauar (2002, p. 126) que, embora aponte o signifícado do termo em seu sentido mais amplo, acaba por elencar uma série de poderes que se confundem com aqueles atribuídos à Comissão de Valores Mobiliários: "Entendemos que a regulação, no atual contexto, abrange: a edição de normas; a fiscalização do seu cumprimento; a atribuição de habilitações (p. ex: autorização, permissão, concessão); a imposição de sanções; a mediação de conflitos (para preveni-los ou resolvê-los, utilizando variadas técnicas, por exemplo: consulta pública; audiência pública, celebração de compromisso de cessação e compromisso de ajustamento)"

${ }_{12}$ Para Aragão (2001, p. 104), "as leis atributivas de poder normativo às entidades reguladoras independentes possuem baixa densidade normativa, a fim de propiciar o desenvolvimento de normas setoriais aptas a, com autonomia e agilidade, regular a complexa e dinâmica realidade social subjacente".
}

Revista do Direito Público, Londrina, v.11, n.1, p.61-84, jan./abr.2016 | DOI: 10.5433/1980-511X.2016v11n1p61 
Confiabilidade: a existência e o crescimento do mercado dependem da confiança que seus diversos protagonistas depositem no sistema. Se o propósito do órgão regulador é favorecer o crescimento do mercado, de modo que ele possa atender sempre às crescentes exigências da sociedade, torna-se imperativa a observação deste fundamento. A regulação deve se dar de forma a criar uma base de confiança que assegure ao detentor de poupança a certeza de que pode atuar no mercado, incorrendo exclusivamente nos riscos próprios do negócio em que quer operar.

Eficiência do mercado: é característica de um mercado livre a sua capacidade de atuar como mecanismo apto a direcionar a poupança da sociedade aos projetos econômicos mais adequados a suas expectativas. Este é um aspecto que se tem de observar e perseguir no trabalho de regulação, na medida em que só assim se consegue o melhor atendimento de anseios da sociedade. Da mesma forma, a minimização dos custos da intermediação desses recursos responde tanto aos interesses das companhias, como dos indivíduos que nelas investem, e será através da eficiência do mercado que tais objetivos poderão ser alcançados: eficiência alocacional e operacional.

Competitividade: a eficiência do mercado depende do grau de competição que se estabeleça entre os seus participantes. Portanto, a regulação terá que se manter sempre atenta a este fundamento, não só evitando ações que venham a inibir a competitividade, mas também assegurando que ela se dê de forma sadia. Além disso, a competição ativa minimiza a necessidade de regulação.

Mercado livre: a liberdade de atuação no mercado e de acesso seus mecanismos é pré-condição de existência de um mercado capaz de desempenhar adequadamente o seu papel. No processo de regulação do mercado de valores mobiliários, devem estar presentes, permanentemente, $\mathrm{o}$ respeito à livre atuação das forças de mercado e o livre acesso ao exercício de atividades e às operações que nele se processem. (COMISSÃO DE VALORES MOBILIÁRIOS, 2014,p 64).

A análise dos fundamentos acima permite concluir que o papel regulador da autarquia abriga não apenas um, mas diversos objetivos, os quais podem ser entendidos como complementares entre si. Isto fica nítido na doutrina de Cantidiano (2011, p. 672), para quem a atividade do órgão regulador acomoda pelo menos quatro escopos principais, descritos abaixo:

Toda a atividade do órgão regulador tem como finalidade (a) estimular a formação de poupança e a sua aplicação em valores mobiliários, (b) promover e assegurar a expansão e o funcionamento eficiente e regular do mercado de valores mobiliários, (c) proteger os titulares de valores mobiliários e os 
investidores contra (i) emissões irregulares de valores mobiliários, contra (ii) atos ilegais dos administradores e controladores das companhias e administradores de carteira e (iii) contra o uso de informação relevante ainda não divulgada ao mercado e (d) assegurar a observância de práticas comerciais equitativas no mercado.

Para o exercício de suas funções normativa, fiscalizatória e sancionatória, a CVM é dotada de poder de polícia, por intermédio do qual pode limitar a liberdade individual em prol de um interesse público ou coletivo. Neste sentido, a autarquia possui meios materiais e institucionais à disposição para o regular desempenho de suas atribuições, cabendo-lhe, por exemplo, iniciar processos administrativos sancionadores ex officio.

\section{O TERMO DE COMPROMISSO NO ÂMBITO DO PROCESSO ADMINISTRATIVO SANCIONADOR}

Os fundamentos e finalidades da disciplina jurídica do mercado de capitais apontam para a necessidade de manutenção de um ambiente em que sejam respeitados os arcabouços legal (ex.: Leis $n^{\circ} 6.385 / 76$ e $n^{\circ} 6.404 / 76$ ), regulatório (ex.: instruções normativas editadas pela CVM), assim como as práticas equitativas por parte de administradores, membros do conselho fiscal e acionistas de companhias abertas, dos intermediários e dos demais participantes do mercado.

Neste sentido, a Lei ${ }^{\circ}$ 6.385/76 confere à CVM o poder-dever de aplicar aos infratores uma série de penalidades, dentre as quais advertências, multas, suspensões, inabilitações temporárias, cassações e proibições temporárias. A aplicação destas penalidades se dá após apuração e verificação, mediante processo administrativo sancionador (PAS), dos atos violadores do arcabouço legal, regulatório e das práticas equitativas. Frise-se que a apenação deve proporcionar maior efeito educativo e preventivo para os participantes do mercado.

A mesma Lei, em seu artigo $11, \S 5^{\circ}$, preceitua que o órgão regulador poderá, a seu exclusivo critério, se o interesse público permitir, suspender, em qualquer fase, o procedimento administrativo instaurado para a apuração de infrações da legislação do mercado de valores mobiliários, se o investigado ou acusado assinar TC (acordo substitutivo), obrigando-se a: I - cessar a prática de atividades ou atos considerados ilícitos pela Comissão de Valores Mobiliários; e II - corrigir as irregularidades apontadas, inclusive indenizando os prejuízos. 
O PAS observará o procedimento fixado pela própria CVM no exercício de seu poder normativo. Atualmente, encontra-se disciplinado na Deliberação $\mathrm{n}^{0}$ 538, de 05 de março de 2008, com as alterações introduzidas pela Deliberação $n^{0} 552 / 08$ (rege o rito ordinário), e também na Instrução n ${ }^{\circ} 545 / 14$ (rege o rito sumário). Ambas dispõem sobre os procedimentos a serem observados na tramitação de PAS instaurados pela autarquia.

Tanto na Deliberação $n^{\circ} 538$ (Art. 13, $\S 4^{\circ}$ ), quanto na Instrução $n^{\circ} 545$ (Art. $2^{\circ}, \S 2^{\circ}$, inc. VI), do ato de intimação deverá constar a advertência de que o acusado poderá propor a celebração de $\mathrm{TC}^{13}$, exceto quando da apuração de irregularidades relacionadas com a Lei n ${ }^{\circ}$ 9.613/98 (que dispõe sobre os crimes de "lavagem" ou ocultação de bens, direitos e valores; a prevenção da utilização do sistema financeiro para os ilícitos previstos nesta Lei, e cria o Conselho de Controle de Atividades Financeiras - COAF), e também nos casos disciplinados na Instrução CVM no 301/99.

O TC é regulamentado pela Deliberação n ${ }^{0}$ 390/2001 (sofreu alterações introduzidas pela Deliberação $n^{\circ} 486 / 05$ ), que aborda o procedimento do instituto em questão, e também pelas Portarias CVM PTE nº 71/05 e CVM PTE n 066/ 08 .

\section{DINÂMICA DO TERMO DE COMPROMISSO NO ARCABOUÇO REGULATÓRIO DO MERCADO DE CAPITAIS BRASILEIRO}

Exceto quando da apuração de irregularidades relacionadas com a Lei no 9.613/98 e também nos casos disciplinados na Instrução CVM no 301/99, a CVM tem autorização para celebrar TC nos demais PAS instaurados, conforme previsto no art. $1^{\circ}, \S 1^{\circ}$ da Deliberação CVM 390/01.

$\mathrm{O}$ interessado na celebração de TC poderá apresentar proposta escrita à CVM, na qual se comprometa a: i) cessar a prática de atividades ou atos considerados ilícitos, se for o caso; e ii) corrigir as irregularidades apontadas, inclusive indenizando os prejuízos causados ao mercado ou à CVM.

O interessado deverá manifestar sua intenção de celebrar TC até o término do prazo para a apresentação de defesa, e sem prejuízo do ônus de apresentação desta. Não obstante, será também admitida a apresentação de proposta de celebração ainda na fase de investigação preliminar. No primeiro caso, a

\footnotetext{
${ }^{13}$ Segundo anotam Wellisch e Santos (2009), o consent decree norte-americano seria a principal inspiração do termo de compromisso no mercado de capitais brasileiro.
}

Revista do Direito Público, Londrina, v.11, n.1, p.61-84, jan./abr.2016 | DOI: 10.5433/1980-511X.2016v11n1p61 
proposta completa deverá ser encaminhada à Coordenação de Controle de Processos Administrativos - CCP até 30 (trinta) dias após a apresentação de defesa. No segundo, deve ser encaminhada à Superintendência responsável pela investigação.

A Procuradoria Federal Especializada (PFE) da CVM será ouvida sobre a legalidade da proposta apresentada pelo interessado. Após ouvida a PFE, o Superintendente-Geral submeterá a proposta de TC ao Comitê de Termo de Compromisso (CTC) ${ }^{14}$, que deverá apresentar parecer (no prazo máximo de 30 dias, contados da data da apresentação do parecer da PFE) sobre a oportunidade e a conveniência na celebração, e a adequação da proposta formulada pelo acusado, propondo ao Colegiado sua aceitação ou rejeição, tendo em vista a oportunidade e a conveniência, a natureza e a gravidade das infrações objeto do processo, os antecedentes dos acusados e a efetiva possibilidade de punição, no caso concreto.

Antes da elaboração de seu parecer, o CTC, se entender conveniente, poderá negociar com o proponente as condições da proposta que lhe pareçam mais adequadas. Esta negociação entre o Comitê e o proponente deverá ser concluída no prazo máximo de 60 (sessenta) dias, sendo facultado a este, ao término das negociações, aditar os termos de sua proposta inicial, no prazo assinalado pelo Comitê. Nesta hipótese de negociação, o prazo para elaboração de parecer pelo Comitê será contado da data em que concluída a negociação ou apresentado o aditamento à proposta inicial, conforme o caso.

A proposta de celebração, acompanhada do parecer do CTC, será submetida à deliberação do Colegiado, que decidirá sobre a sua aceitação ou rejeição. Aprovadas as condições, lavrar-se-á termo que será assinado pelo Presidente da CVM, pelas partes interessadas e duas testemunhas.

O TC suspende o processo administrativo em curso, pelo prazo estipulado para o cumprimento do compromisso. Por outro lado, as condições do termo, após aprovadas pelo Colegiado, não poderão ser alteradas, a menos que haja uma nova deliberação após requerimento da parte interessada.

A celebração de compromisso não importará em confissão quanto à matéria de fato, nem reconhecimento de ilicitude da conduta analisada no

\footnotetext{
${ }^{14}$ A composição atual do Comitê está disciplinada no artigo $2^{\circ}$ da Portaria CVM PTE $n^{\circ} 71$, de 17 de agosto de 2005, com redação dada pela Portaria CVM PTE n ${ }^{\circ} 066$, de 01 de abril 2008. Art. $2^{\circ}$ - O Comitê de Termo de Compromisso será composto pelos titulares das seguintes Superintendências: I - Superintendência-Geral - SGE; II - Superintendência de Fiscalização Externa - SFI; III Superintendência de Relações com Empresas - SEP; IV - Superintendência de Relações com o Mercado e Intermediários - SMI; V - Superintendência de Normas Contábeis e Auditoria - SNC; e VI - Superintendência de Processos Sancionadores - SPS.
}

Revista do Direito Público, Londrina, v.11, n.1, p.61-84, jan./abr.2016 | DOI: 10.5433/1980-511X.2016v11n1p61 
processo que lhe tenha dado origem, sendo estas as grandes vantagens para os acusados da realização de práticas ilegais.

Da decisão do Colegiado que rejeita a proposta de TC não cabe recurso ao Conselho de Recurso do Sistema Financeiro Nacional, porque a discricionariedade para aprovar ou não a celebração do acordo é exclusiva da autarquia, conforme o art. $11, \S 5^{\circ}$ da Lei $n^{\circ} 6.385 / 76$.

\section{ANÁLISE DOS PRINCIPAIS ASPECTOS TEÓRICOS E PRÁTICOS DO TERMO DE COMPROMISSO}

Segundo Silveira (2006), a natureza jurídica do TC se aproxima da transação, na medida em que caracteriza um acordo entre o acusado e a CVM. $\mathrm{Na}$ verdade, pode o acordo substitutivo ser compreendido como um negócio jurídico, já que combina características da transação civil e do ato administrativo discricionário ${ }^{15}$, que é aquele em que a Administração possui alguma liberdade de avaliação ou decisão.

A natureza de negócio jurídico fica clara na análise de Muto e Yokoi (2008), para quem cabe à CVM aceitar os termos propostos, recusar ou ainda discutir melhorias, opções estas típicas dos agentes que se dispõem a celebrar negócios jurídicos, mas sem necessidade de aprovação judicial de eventual compromisso celebrado. Deve-se frisar que a dinâmica do termo de compromisso na realidade brasileira se diferencia, por exemplo, daquela presente no modelo norte-americano, em que a eficácia do consent decree depende de homologação judicial.

Através do TC, há a possibilidade de reparação dos danos aos investidores lesados, embora estes sequer sejam partes no processo. Lecionam Eizirik et al (2011) que a exigência de reparação de danos só ocorre se houver acontecido algum prejuízo quantificável ou contra prejudicados identificáveis para que se possa atribuir a cada um deles o valor a ser indenizado. Neste aspecto vale mencionar que o art. 10 da Deliberação 390/01, dispõe que, na hipótese da existência de dano a investidores, há a possibilidade da CVM, a seu critério, notificar-lhes para que apresentem maiores informações sobre a quantificação do valor que poderá vir a ser-lhes pago para reparar seus danos.

\footnotetext{
${ }^{15}$ Ato administrativo é a declaração unilateral do Estado no exercício de prerrogativas públicas, manifestada mediante comandos concretos complementares da lei expedidos a título de lhe dar cumprimento e sujeitos a controle de legitimidade por órgão jurisdicional (MELLO, 2003).
}

Revista do Direito Público, Londrina, v.11, n.1, p.61-84, jan./abr.2016 | DOI: 10.5433/1980-511X.2016v11n1p61 
No caso acima, o investidor lesado apenas se limitará a prestar informações relativas à extensão dos danos que tiver sofrido e ao valor da reparação. Contudo, na hipótese de existirem investidores prejudicados em número indeterminado e de identidade desconhecida, a autarquia poderá, em comum acordo com o proponente e às suas expensas, fazer publicar editais convocando os investidores para que estes sejam identificados e para que quantifiquem os valores individuais a serem pagos a título de indenização.

Até o ano de 2006, frisa Silveira (2006), as principais obrigações impostas aos compromitentes nos termos de compromisso aceitos foram: doações a instituições assistenciais, recomposição de dados aos investidores lesados e dos custos incorridos pela CVM com a instauração do procedimento administrativo, implementação de política interna de negociação com valores mobiliários em companhias abertas, realização de treinamentos e seminários e distribuição de materiais sobre regulamentação aplicável, com finalidade educativa, realização de oferta pública para a aquisição de ações e aquisição de ações de acionistas minoritários que não aderiram a oferta pública.

Quanto à executividade, a CVM pode promover a execução judicial do termo, que é um título executivo extrajudicial, conforme o artigo $11, \S 7^{\circ}$ da Lei $\mathrm{n}^{\circ} 6.385 / 76$, em conjunto com a retomada do processo administrativo sancionador que estava suspenso por ocasião do acordo. Esta conduta não é considerada bis in idem, tendo em vista que o termo de compromisso não aplica penalidades, mas sim impõe obrigações (MORAES, 1998).

Antes de sua alteração pela Lei 10.303/01, a parte final do $\S 7^{\circ}$ do artigo 11 da Lei 6.385/76 dispunha que o descumprimento do termo de compromisso caracterizaria crime de desobediência, conforme o artigo 330 do Código Penal. A doutrina criticava este parágrafo. Para EIZIRIK et al (2011), não se configuraria este crime por não se expedir, quando da assinatura do termo de compromisso, qualquer tipo de ordem pela CVM. Por ter o compromisso uma natureza negocial, não há ordem, mas tão somente um simples acordo.

Outra questão importante, destacada por Silveira (2006), é que o descumprimento do termo de compromisso não pode ser considerado como circunstância agravante pela CVM na aplicação de penalidade caso o acusado, não cumprindo o acordo, venha a ser condenado no processo administrativo sancionador. O argumento é o de que o acordo apenas impõe a suspensão do PAS instaurado contra o acusado, logo, a apenação do acusado, após apuração da ilicitude das condutas apontadas pela CVM como irregulares, não poderia ser agravada levando-se em consideração o não cumprimento do termo. 
Uma vez confirmado que o termo de compromisso firmado entre a CVM e o acusado foi decorrente de ato com vício de legalidade, de modo que não tenham sido observadas a conveniência e oportunidade, pode um interessado requerer em juízo a desconstituição do termo de compromisso firmado por meio de medida judicial. Entretanto a desconstituição do termo de compromisso eivado de ilegalidade não afasta a possibilidade de ser firmado um novo termo, desde que sem vícios (SILVEIRA, 2006).

No decorrer dos anos, observou-se a alteração na modalidade de obrigações assumidas pelos compromitentes. No início, a obrigação era mais relacionada a ministrar seminários ou a elaborar material educativo a ser distribuído aos investidores. A partir do ano 2000, verificou-se que em muitos termos de compromisso consta a obrigação de doação a programas sociais e a entidades filantrópicas. Em 2005, houve aumento de atribuição de valores à CVM a título de ressarcimento de despesas, doação, multa, reparação de danos causados à autarquia e ao mercado de capitais. A partir de 2006, percebeu-se mais frequente a obrigação de pagar determinada quantia à CVM, sem especificação do título (TANJ, 2009).

Tal como previsto na legislação pertinente, a CVM pode rejeitar propostas de termos de compromisso. No ano de 2005 foi feito um levantamento dos inquéritos para averiguar motivos que levaram a CVM rejeitar ou aceitar o termo de compromisso, cujos dados são seguintes dados: no caso de aprovação da proposta de termo de compromisso pela CVM, esta fundamentou-se principalmente na presença dos elementos de conveniência e oportunidade, destacando-se a recomposição dos danos como fator determinante para aceitação do termo. Por outro lado, no caso de rejeição da proposta, esta baseouse principalmente na ausência dos elementos conveniência e oportunidade e na falta de reparação dos danos causados e nos casos de assunção de compromisso da prática supostamente irregular a partir da data da celebração do termo, uma vez que tal conduta já é obrigatória pela própria regulamentação (SILVEIRA, 2006).

Em 15 de janeiro de 2009, foi divulgada uma pesquisa na qual foram analisados 184 termos de compromissos celebrados entre a CVM e administrados no período entre 1998 e 2008. Verificou-se que houve um elevado índice de adimplemento das obrigações pelos compromitentes. Aconteceu apenas um inadimplemento (IA CVM n ${ }^{\circ}$ 04/99), que, segundo Tanji (2009, p. 101), foi seguido de: "(i) julgamento do feito pelo Colegiado da CVM com a aplicação de penalidades administrativas; (ii) ajuizamento de ação coletiva pelo Ministério 
Público Federal" - MPF em face dos compromitentes na qual a CVM figurou como assistente da parte autora" $"$.

Na prática, muitos termos de compromisso têm um alto valor pecuniário, contudo, há acusado que, mesmo ciente de sua inocência, prefere assinar o termo e pagar, mantendo a reputação, uma vez que uma pendência administrativa afasta a oportunidade de bons negócios, além disso, prefere não correr o risco da condenação (CARRION, 2011). Vale ressaltar que, quanto "aos valores atribuídos aos prejudicados, àqueles que sofreram danos decorrentes da conduta do compromitente, observa-se montante significativo, mas menor em relação àquele atribuído à CVM" (TANJI, 2009, p. 102).

Em interessante exercício de aplicação da metodologia de tese/antítese, a Revista Capital Aberto publicou dois artigos de opinião, em que os autores deveriam enfrentar a seguinte questão: "Os termos de compromisso estão sendo utilizados em demasia pela CVM?". Segundo Chaves (2010), o mecanismo tem sido usado em demasia pela autarquia, o que remete a uma necessidade de maior rigor para a aprovação dos acordos. Para o autor, em casos graves, como na hipótese de prática de uso indevido de informação privilegiada, estes não deveriam ser celebrados. Em sentido contrário, Amendolara (2010) defende que não há uso excessivo, na medida em que se trata de um instituto eficaz, que, na prática, põe fim a processos que muitas vezes poderiam se arrastar por longos períodos, sem garantia de condenação dos infratores.

\section{O TERMO DE COMPROMISSO NO PERÍODO 2009/2014: BANALIZAÇÃO DO USO DO INSTRUMENTO REGULATÓRIO PELA COMISSÃO DE VALORES MOBILIÁRIOS?}

Para uma melhor a avaliação do TC como instrumento regulatório no âmbito do mercado de capitais brasileiro, utilizou-se a opção metodológica de realização de pesquisa sobre dados empíricos relacionados ao referido instrumento.

Considerando a necessidade de recorte, privilegiou-se o período compreendido entre os anos de 2009 e 2014, muito embora o mecanismo venha sendo utilizado desde o ano de 1998 (isto é, logo no ano subsequente a sua introdução ao ordenamento jurídico, em 1997). Até porque, foram encontradas

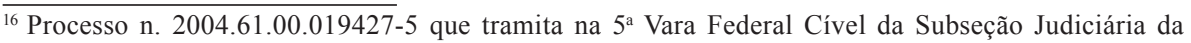
Capital do Estado de São Paulo.

Revista do Direito Público, Londrina, v.11, n.1, p.61-84, jan./abr.2016 | DOI: 10.5433/1980-511X.2016v11n1p61 
na doutrina abordagens sobre o tema, que, em sua maioria, catalogavam informações referentes a dados concretos relativos ao período anterior a 2009. Deste modo, o recorte proposto possibilitaria uma visão mais atual da dinâmica recente da utilização do instrumento.

Neste sentido, foram levantados os TC aprovados nos anos de 2009 (sessenta e oito acordos aprovados), 2010 (oitenta acordos aprovados), 2011 (setenta acordos aprovados), 2012 (sessenta e três acordos aprovados), 2013 (oitenta e nove acordos aprovados) e 2014 (35 acordos aprovados), mediante pesquisa junto a CVM. Os números refletem os quantitativos anuais de acordos substitutivos aprovados pelo órgão regulador em cada ano do período selecionado, e totalizam 405 acordos. Frise-se que: i) há casos em que os acordos "aprovados" em determinado ano são assinados somente no ano seguinte, razão pela qual optou-se pela contagem somente daqueles aprovados; ii) em diversos casos, há mais de um acordo substitutivo aprovado no âmbito de um mesmo PAS.

Percebe-se, através dos dados consolidados, a utilização demasiada, pela CVM, do permissivo que lhe possibilita a celebração, como resposta alternativa à aplicação das penalidades previstas na Lei 6.385/76, do acordo substitutivo com os infratores dos arcabouços legal e regulatório, bem como das práticas equitativas no mercado de capitais. Registre-se que também foram observados casos em que as propostas de acordos substitutivos foram rejeitadas pela autarquia ${ }^{17}$.

Os dados indicam que, embora o acordo possa ser compreendido como um importante mecanismo no âmbito da regulação do mercado de capitais porque caracteriza uma maior abertura do sistema normativo aos agentes do mercado e garante espaço para reações alternativas à pura e simples aplicação de penalidades, com possibilidades de negociação entre a autarquia e os acusados, para suspender e encerrar processos, fixar indenizações etc , o seu uso demasiado implica em desvirtuamento de suas finalidades, dos fundamentos da disciplina normativa do mercado e do conjunto de funções atribuídas à CVM.

\footnotetext{
${ }^{17} \mathrm{Na}$ apreciação de proposta de termo de compromisso referente ao PAS RJ2012/9808, o Colegiado, em 06/01/2015, deliberou por unanimidade, ser inoportuna e inconveniente a aceitação das propostas, pois a eventual celebração de termo de compromisso com os acusados não traria economia processual significativa para a CVM, tendo sido as propostas apresentadas rejeitadas. Outro ponto importante: a reincidência é um dos motivos que leva a CVM a recusar a proposta de termo de compromisso, tal como aconteceu em 17 de junho de 2015, quando o Colegiado decidiu por unanimidade pela rejeição da proposta de termo de compromisso elaborada pela União Federal, que foi acusada de descumprimento do Artigo 115 da Lei das S.A em razão de sua participação na AGE que deliberou pela aceitação dos termos da MP 579 - e que provocou prejuízos à estatal (AMEC, 2015).
}

Revista do Direito Público, Londrina, v.11, n.1, p.61-84, jan./abr.2016 | DOI: 10.5433/1980-511X.2016v11n1p61 
Embora não seja possível precisar, unicamente a partir dos dados levantados, que o prosseguimento dos PAS, sem a aprovação dos acordos, caracterizaria um ambiente jurídico melhor, supõe-se que a utilização dos TCs em tão larga escala importa em banalização do instrumento ${ }^{18}$. Acredita-se que a ciência, por parte dos players do mercado em geral, de que bastaria ao infrator, mediante a celebração do termo, simplesmente se comprometer a cessar a prática de atividades ou atos considerados ilícitos pela CVM e corrigir as irregularidades apontadas (inclusive indenizando prejuízos), constitui uma espécie de incentivo para a prática de infrações, não sendo apto ao seu desestímulo.

A confiabilidade, um dos fundamentos da regulação, indica que a disciplina normativa do mercado deve se dar de forma a criar uma base de confiança que assegure ao detentor de poupança a certeza de que pode atuar incorrendo exclusivamente nos riscos próprios do negócio em que quer operar. As infrações ao arcabouço regulatório corroem a confiança dos investidores no mercado. E um mercado jamais será eficiente se não há confiança no seu regular funcionamento, para o que é necessário o respeito ao conjunto de regras do jogo.

Da mesma forma, a atuação da CVM deve se dar no sentido de desestimular práticas ilegais, zelar por proteger os titulares de valores mobiliários contra emissões irregulares e atos ilegais de administradores e acionistas controladores de companhias ou administradores de carteira de valores mobiliários; evitar ou coibir modalidades de fraude ou manipulação destinadas a criar condições artificiais de demanda, oferta ou preço de valores mobiliários negociados no mercado; assegurar o acesso do público a informações sobre valores mobiliários negociados e as companhias que os tenham emitido; assegurar a observância de práticas comerciais equitativas no mercado de valores mobiliários; estimular a formação de poupança e sua aplicação em valores mobiliários; promover a expansão e o funcionamento eficiente e regular do mercado de ações e estimular as aplicações permanentes em ações do capital social das companhias abertas.

\footnotetext{
${ }^{18}$ Há duas questões que podem, talvez, constituir uma espécie de incentivo informal para a utilização dos acordos substitutivos em larga escala: 1) a dificuldade da CVM no que diz respeito à agilidade no julgamento dos processos (há processo de 2010 sendo julgados somente agora, em 2015); 1) as penas pecuniárias (atualmente, não poderá exceder o maior destes valores: i) $\mathrm{R} \$ 500.000,00$; ii) cinquenta por cento do valor da emissão ou operação irregular; ou iii) três vezes o montante da vantagem econômica obtida ou da perda evitada em decorrência do ilícito) previstas na Lei $\mathrm{n}^{\circ}$ 6.385/76, consideradas baixas (montantes fixados pela Lei 9.457/97, que alterou a Lei $\mathrm{n}^{\circ} 6.385 / 76$. Todavia, acredita-se que tais fatores não podem ser utilizados como justificativas para o desvirtuamento do instituto do termo de compromisso.
}

Revista do Direito Público, Londrina, v.11, n.1, p.61-84, jan./abr.2016 | DOI: 10.5433/1980-511X.2016v11n1p61 
Não se pode esquecer que, se na aplicação das penalidades pela prática de atos violadores do arcabouço legal, regulatório e das práticas equitativas, a apenação deve proporcionar maior efeito educativo e preventivo para os participantes do mercado (com objetivo de desestimular práticas ilegais), podese, com o uso desproporcional do acordo substitutivo, gerar um efeito justamente inverso, ou seja, a disseminação da ideia de que os atos violadores e práticas não equitativas podem ser "apagados" mediante a celebração do termo de compromisso. Este possível efeito negativo é corroborado pela própria disciplina jurídica do tema, que indica que o acordo, desde que proposto, aceito e cumprido, não importará confissão quanto à matéria de fato, nem reconhecimento de ilicitude da conduta analisada.

\section{CONSIDERAÇÕES FINAIS}

Com a presente pesquisa, foi possível compreender o TC como um importante mecanismo regulatório à disposição do órgão regulador do mercado de capitais brasileiro, a CVM.

Através deste instrumento, a autarquia poderá celebrar acordos substitutivos com os infratores do arcabouço legal e regulatório, ou com os responsáveis pela realização de práticas não equitativas no âmbito do mercado. Os termos constituem uma possibilidade de reação alternativa às penalidades listadas na Lei $n^{\circ} 6.385 / 76$, caracterizando um sistema normativo aberto, que possibilita uma maior aproximação entre o órgão regulador e os agentes do mercado.

Como resposta ao problema de pesquisa que orientou a presente investigação, acredita-se que as previsões nos âmbitos legal e regulatório, que contemplam a possibilidade de o acusado, no âmbito do processo administrativo sancionador, propor a celebração de termo de compromisso, não tornam, por si só, oportuna e conveniente a celebração de compromissos em demasiada escala.

Tratando-se de instrumento regulatório, a sua utilização deve estar adstrita aos mesmos fundamentos que inspiram o arcabouço regulatório, como interesse público, confiabilidade e eficiência do mercado. Da mesma forma, aquele que o utiliza, no caso a CVM, deve pautar-se pela observância de suas finalidades institucionais, tais como proteger os titulares de valores mobiliários, evitar ou coibir modalidades de fraude ou manipulação, assegurar a observância de práticas comerciais equitativas no mercado de valores mobiliários, estimular a formação de poupança e sua aplicação em valores mobiliários, promover a expansão e o funcionamento eficiente e regular do mercado e estimular as aplicações permanentes em ações do capital social das companhias abertas. 
Do exame dos PAS instaurados entre 2009 e 2014, chegou-se ao número total de 405 termos aprovados pelo órgão regulador, resultados que caracterizam uma acentuada utilização deste instrumento regulatório. Acredita-se que este uso demasiado da reação alternativa às penalidades implica em desvirtuamento das finalidades do próprio acordo substitutivo enquanto mecanismo de regulação, assim como viola fundamentos da disciplina normativa do mercado e também do conjunto de funções atribuídas à CVM.

Deve, portanto, ser restringido o uso do TC a hipóteses pontuais, em que configure interesse público a reação alternativa à aplicação das penalidades previstas em Lei, considerados os fundamentos da regulação e as finalidades da própria CVM. Neste sentido, sugere-se que: i) em regra, o uso deveria estar adstrito aos casos previstos na Instrução CVM n ${ }^{\circ} 545 / 14$, que prevê a aplicação do PAS em seu rito sumário, para apuração das chamadas infrações objetivas, relacionadas a uma conduta omissiva dos agentes de mercado; ii) excepcionalmente, com um maior rigor, o uso nas hipóteses de determinadas infrações gerais leves (cuja apuração se daria na forma da Deliberação CVM $n^{0} 538 / 08$, que regula o PAS em seu rito ordinário), sendo vedado em casos graves como o uso indevido de informação privilegiada.

\section{REFERÊNCIAS}

\section{AMEC. CVM rejeita por unanimidade termo de compromisso da} união no caso Eletrobrás. Disponível em: < http://www.amecbrasil.org.br/ cvm-rejeita-por-unanimidade-termo-de-compromisso-da-uniao-no-casoeletrobras/>. Acesso em: 12 jul. 2015.

AMENDOLARA, Leslie. Instituto eficaz: mecanismo põe fim a processos que se arrastariam por longos períodos sem garantia de condenação.

Revista Capital Aberto, [São Paulo], n. 78, fev. 2010, p. 47. Disponível em: $<$ http:/www.capitalaberto.com.br/pageflip/78/Ed\%2078/assets/basic-html/ page46.html>. Acesso em: 06 ago. 2015.

ARAGÃO, Alexandre Santos de. O poder normativo das agências reguladoras. Revista Trimestral de Direito Público, São Paulo, n. 36, 2001.

ASSAF NETO, Alexandre. Mercado financeiro. 11. ed. São Paulo: Atlas, 2012. 
CANTIDIANO, Luiz Leonardo. O papel regulador da CVM. In: WALD, Arnoldo (Org.) Direito empresarial: mercado de capitais. São Paulo: Revista dos Tribunais, 2011. v.8.

CARRION, Bruna Maia. Cálculo de risco: por que cada vez mais milionários termos de compromisso se tornaram uma saída conveniente para a CVM e para os acusados. Revista Capital Aberto, [São Paulo], n. 91, mar. 2011. Disponível em: <http://www.capitalaberto.com.br/temas/calculo-de-risco/ \#.VZxO4FK4JMp>. Acesso em: 06 jul. 2015.

CHAVES, Renato. É preciso mais rigor em casos graves, como insider trading, o regulador não deveria prever acordos. Revista Capital Aberto, [São Paulo], n. 78, fev. 2010, p. 46. Disponível em: <http:// www.capitalaberto.com.br/pageflip/78/Ed\%2078/assets/basic-html/ page46.html>. Acesso em: 06 ago. 2015.

COMISSÃO DE VALORES MOBILIÁRIOS (Brasil). O mercado de valores mobiliários brasileiro. 3.ed. Rio de Janeiro: CVM/SOI, 2014. Disponível em: < http://www.portaldoinvestidor.gov.br/portaldoinvestidor/ export/sites/portaldoinvestidor/publicacao/Livro/LivroTOP-CVM.pdf>. Acesso em: 10 jun. 2015.

COSTA, Gabriel Carvalho da; BRIGAGÃO, Pedro Henrique Castello VIEIRA, Victor da Silveira. O dever de diligência não julgado: casos encerrados pela CVM com a celebração de termos de compromisso. Disponível em: $<$ http://www.puc-rio.br/pibic/relatorio_resumo2013/ relatorios_pdf/ccs/DIR/DIR-Gabriel $\% 20$ Carvalho\%20Pedro $\%$ 20Brigag\%C3\%A3o-Mais .pdf $>$. Acesso em: 13 jul. 2015.

EIZIRIK, Nelson, et. al. Mercado de capitais: regime jurídico. 3. ed. Rio de Janeiro: Renovar, 2011.

ELIAS, Luiz Antônio Rodrigues; GAMA, Eduardo Guimarães. O mercado de ações no Brasil. In: CASTRO, Hélio Oliveira Porto Carrero de (Coord.). Introdução ao mercado de capitais. Rio de Janeiro: IBMEC, 1979, p. $135-152$. 
FORTUNA, Eduardo. Mercado financeiro: produtos e serviços. 15. ed., rev. e atual. Rio de Janeiro: Qualitymark, 2002.

GASPARINI, Diógenes. Direito administrativo. 14. ed. rev. São Paulo: Saraiva, 2009.

GUERREIRO, José Alexandre Tavares. Sobre o poder disciplinar da CVM. Revista de Direito Mercantil, São Paulo, v. 43, 1981.

KÜMPEL, Siegfried. Direito do mercado de capitais: do ponto de vista do direito europeu, alemão e brasileiro. Rio de Janeiro: Renovar, 2007.

LAMEIRA, Valdir de Jesus. Mercado de capitais. 2. ed. Rio de Janeiro: Forense Universitária, 2003.

MEDAUAR, Odete. Regulação e auto regulação. Revista de Direito Administrativo, Rio de Janeiro, n. 228, abr./jun. 2002.

MELlO, Celso Antônio Bandeira de. Curso de direito administrativo. 15. ed. São Paulo: Malheiros, 2003.

MORAES, Luiza Rangel de. Considerações sobre o consent decree e sua aplicação no âmbito da disciplina do mercado de valores mobiliários. Revista de Direito Bancário e do Mercado de Capitais, São Paulo, n. 4, jul-set, 1998.

MOREIRA, Egon Bockmann. Conselho Monetário Nacional, Banco Central do Brasil e Comissão de Valores Mobiliários. Considerações acerca de sua natureza jurídica, em face das chamadas "Agências Administrativas". Revista de Direito Mercantil, v.38, n. 116, out./dez. São Paulo, Malheiros, 1999.

MOREIRA NETO, Diogo de Figueiredo. Curso de direito administrativo: parte introdutória, parte geral e parte especial. 11. ed.,rev. e atual. Rio de Janeiro: Forense, 1998.

MUTO, Silvio; YOKOI, Yuki. Colegiado da CVM amplia o uso de termos de compromisso. Revista Capital Aberto, [São Paulo]. n. 60, 2008. Disponível 
em: $<$ http://www. capitalaberto.com.br/temas/colegiado-da-cvm-amplia-usode-termos-de-compromisso/\#.VZxPO 1K4JMp>. Acesso em: 07 jul. 2015.

NAZAR, Nelson. Direito econômico. 2. ed. rev., ampl. e atual. Bauru: EDIPRO, 2009.

ROSA, Maria Eduarda Fleck da. O poder normativo da comissão de valores mobiliários. São Paulo, 2012. Dissertação (Mestrado em Direito). Pós-Graduação em Direito da Faculdade de Direito da Universidade do Estado de São Paulo - USP.

SILVEIRA, Sandra Maria Bittencourt da. O instituto do termo de compromisso no sistema de regulação do mercado de capitais brasileiro. São Paulo, 2006. Dissertação (Mestrado em Direito). Pósgraduação em Direito da Faculdade de Direito da Pontifícia Universidade Católica - PUC.

TANJI, Márcia. Mercado de capitais brasileiro e tutela coletiva dos interesses. São Paulo, 2009. Dissertação (Mestrado em Direito).

Pós-graduação em Direito da Faculdade de Direito da Universidade de São Paulo - USP.

VASCONCELLOS, Marco Antonio Sandoval de; GARCIA, Manuel E. Fundamentos de economia. 2. ed. São Paulo: Saraiva, 2005.

WELLISCH, Julya Sotto Mayor; SANTOS, Alexandre Pinheiro dos. O termo de compromisso no âmbito do mercado de valores mobiliários. Interesse Público - IP, Belo Horizonte, v. 11, n. 53, jan./fev. 2009.

Artigo recebido em: 25/08/2015 Aprovado para publicação em: 01/03/2016

Como citar: CHAVES, Vinicius Figueiredo Chaves. SOARES, Abel Rafael. Análise Crítica da Aplicação do Termo de Compromisso como Instrumento Regulatório do Mercado de Capitais. Revista do Direito Público. Londrina, v.11, n.1, p.61-84, jan/abr.2016. DOI: 10.5433/1980511X.2016v11n1p61. ISSN: 1980-511X. 